\title{
Pharmacovigilance of Neuroleptics and Benzodiazepines in the Psychiatric Teaching Hospital of Benin Republic
}

\author{
Allabi $\mathrm{AC}^{1 *}$, Klikpo $\mathrm{E}^{2}$, Lonmandon $\mathrm{SC}^{1}$ and Tognide $\mathrm{CM}^{2}$ \\ ${ }^{1}$ Pharmacology Unit, Faculty of Health Sciences, University of Abomey Calavi, 01 BP 188 Cotonou, Benin \\ ${ }^{2}$ National Hospital Center, University of Psychiatry of Cotonou, Benin
}

\begin{abstract}
Background: Data on adverse drug reactions (ADRs) related to neuroleptics and benzodiazepines in subSaharan Africa psychiatry setting are few indicating the need for psychotropic drugs safety surveillance in clinical care.

Objective: To determine profile of the drugs prescribed, incidence, type and risk factors associated with adverse drug reactions (ADRs) among patients on neuroleptics and benzodiazepines.

Methods: Patients initiated on neuroleptics and/or benzodiazepines between March 2014 and September 2014 were evaluated in a prospective cohort analysis. Prospective study of active pharmacovigilance during six months was performed. Each patient was followed for two months. The French method was used to determine the causality assessment.

Results: 86 inpatients or outpatients were enrolled. $65.12 \%$ experienced a side event (SE). Among them $22.09 \%$ had insomnia, $17.44 \%$, drowsiness; $5.81 \%$, dyskinesia; $4.65 \%$, an appetite increase and $4.65 \%$, headaches. The percentages of patients with $1,2,3,4$ and 5 side events were $39.28 \%, 41.07 \%, 8.92 \%, 7.14 \%$ and $3.57 \%$ of the $65.12 \%$ respectively. The average number of side events per patient was similar in hospitalized patients and in those treated ambulatory (1.97 vs. 1.92). The causality assessment of the side events to the drugs prescribed to each patient is predominantly doubtful (52.29\%). It is likely in $44.95 \%$, very likely in only $1.83 \%$ of the cases and plausible in $0.92 \%$ of the patients. All SEs occurred during the first month, most during the first week. The management of adverse drugs reactions led to drug doses reduction only in $23 \%$ of the cases while responsible drugs were stopped in $5.77 \%$ of the cases.

Conclusion: The relatively high frequency of typical antipsychotics of use and low daily dose of benzodiazepine among our patients merit further investigation and systematic efficacy and safety monitoring. Typical antipsychotics should be made more available and monotherapies should be encouraged. The pharmacovigilance should be developed in the country by installing a National Center and by training health professionals.
\end{abstract}

Keywords: Adverse drugs reactions; Neuroleptics; Benzodiazepine; Benin; Pharmacovigilance

\section{Introduction}

The World Health Organization (WHO) defines health as: "A state of complete physical, mental and social wellbeing and not just an absence of disease or infirmity." Mental health is the ability to deal with normal stress situations of life, to work productively and contribute to community wellbeing. Conversely, psychiatric disorders hinder everyday life with emotional, cognitive, interpersonal and behavioral repercussions.

About 450 million people suffer from mental or behavioral troubles in the world [1] and 33\% of the total incapacity years are imputable to neuropsychiatric problems. A study by Wittchen et al. in 2011 in the European Union (EU), Switzerland, Iceland and Norway, revealed that $38 \%$ of the population of the UE has a trouble of the psyche once a year [2]. In Morocco, a 2005 study on 5, 498 persons over 15, established the percentage of people with a recurrent disorder at $48.9 \%$, that of severe depression at $26.5 \%$ and that general anxiety at $9.3 \%$ [3]. In Benin Republic, a 2013 study on a sample of 1, 530 people found the prevalence of schizophrenia to be $1.1 \%$ [4].

Psychotropic drugs are used to manage psychiatric troubles in combination with other means such as psychotherapy and social rehabilitation. Psychiatric diseases are marked by biochemical alterations in the brain and the drugs used against them act either on the concentration of the neurotransmitters of the synaptic cleft or on their ability to bind to receptors [5] affecting directly brain functioning and producing undesirable changes in behavior. According to their action, psychotropic drugs are distinguished as psycholeptiques (hypnotics, narcoleptics), psychoanaleptics (antidepressors) and psychodysleptics (which induce toxicomania) [6]. Polymedication is frequent in psychiatry which can increase the risk of adverse effects or drug interactions [7] the most prescribed categories of drugs being psychotropics such as neuroleptics and benzodiazepines (21.4\%-France and 15.5\%-Spain) [8]. Moreover, rare clinical trials of psychotropics are conducted in sub-Saharan Africa and patients are selected according to stringent criteria and comorbid medical conditions are usually excluded. Furthermore, there is a paper written on clinical trials, mostly those in psychiatry indicates that ADRs are not always constantly reported [9] and there is an issue showing that

*Corresponding author: Aurel Constant E Allabi, Pharmacology Unit, Faculty of Health Sciences, University of Abomey Calavi, 01 BP 188 Campus of the Champ de Foire, Cotonou-Republic of Benin, Benin, Tel: +22996722151; E-mail: acallabi@hotmail.com

Received: November 15, 2017; Accepted December 02, 2017; Published December 09, 2017

Citation: AllabiAC, KlikpoE, Lonmandon SC, Tognide CM(2017)Pharmacovigilance of Neuroleptics and Benzodiazepines in the Psychiatric Teaching Hospital of Benin Republic. J Pharmacovigil 5: 249. doi:10.4172/2329-6887.1000249

Copyright: $\odot 2017$ Allabi AC, et al. This is an open-access article distributed under the terms of the Creative Commons Attribution License, which permits unrestricted use, distribution, and reproduction in any medium, provided the original author and source are credited. 
an appropriate data might be distorted in some cases [10]. This implies good phase IV studies to ensure patients' safety particularly among African patients.

Pharmacovigilance has been defined by the World Health Organization (WHO) as the science and activities related to the detection, assessment, understanding and prevention of adverse drug effects [11]. In Benin Republic, Pharmacovigilance is still in an embryonary state [12]. No published data exists on the pharmacovigilance of psychotropic drugs including neuroleptics and benzodiazepines. This is the reason behind this first report of adverse drug reactions.

\section{Methods}

It is an observational and prospective study conducted at the National Psychiatry University Hospital of Cotonou in Benin from March to September 2014 including 18 year old or older patients, hospitalized or ambulatory followed up and under neuroleptics and/or benzodiazepines. The variables studied were the type and moment of side events, the clinical outcome of treatment, age, sex, religion, ethnicity, marital status, profession and level of study, number of drugs prescribed, therapeutic observance, polymedication and comorbidity.

The data was collected during one on one consultation or over the phone using a predetermined questionnaire. Data entry was done using the following software: Microsoft Office Excel 2007 version and Epi Data 3.1. Data analysis consisted in the description of the variables and the study of possible relations among qualitative variables on the one hand and between the qualitative variables on the other hand. Chisquare and Student's exact tests have been used to look for possible relations between the variables. A logistic multivariate regression analysis with the version 11.0 of the Stata software was utilized to look for factors linked to the side events. A 5\% significance threshold has been adopted. The study has been accepted by the Committee on Ethics and Research of Applied Biomedical Sciences (CER-ISBA N ${ }^{\circ} 41 \mathrm{du}$ 03/07/2014). The enlightened consents of patients or of their relatives were received and the data collected was treated confidentially with respect of anonymity.

\section{Results}

\section{Age}

$17.44 \%$ of the patients belonged to the age group (18-24) and 2.33\% to the age group (65-70). The most represented age group was (25-34) with $34.88 \%$ of the patients as shown by Table 1 .

\section{Sex}

The sex ratio (W/M) of the patients was 1.1 (52.33\% of women).

\section{Probable diagnoses}

Patients' pathologies are dominated by chronic psychoses as one can see in Table 2 . Comorbidity was present in $11.63 \%$ of the case. The other diseases were high blood pressure $(5.8 \%)$, diabetes $(2.3 \%)$, asthma, HIV infection and epilepsy (1.16\% each). The medical histories recorded showed that $22 \%$ of the patients were taking psychoactive drugs; $12.79 \%$, tobacco, $12.79 \%$ alcohol; $4.65 \%$, cannabis; and $2.33 \%$ coffee. Some patients were taking several of these substances.

\section{Profile of the drugs prescribed}

Chlorpromazine, Haloperidol, Trihexyphenidyle, Amitriptyline and Diazepam were the most prescribed drugs in the department. Table 3 shows all the drugs prescribed with their pharmacological classes and doses and (Figure 1) indicates that the most prescribed neuroleptics were the first generation ones: Chlorpromazine and Haloperidol (42.22\% for each). Diazepam was the main benzodiazepine used. The average dose in milligrams is obtained by dividing all doses prescribed during a day by the number of patients put under a particular medication.

\begin{tabular}{|c|c|c|}
\hline Age & Number & Frequency in \% \\
\hline $18-24$ & 15 & 17.44 \\
\hline $25-34$ & 30 & 34.88 \\
\hline $35-44$ & 14 & 16.28 \\
\hline $45-54$ & 19 & 22.09 \\
\hline $55-64$ & 6 & 6.98 \\
\hline $65-70$ & 2 & 2.33 \\
\hline Total & 86 & 100 \\
\hline
\end{tabular}

Table 1: Patients' age.

\begin{tabular}{|c|c|c|c|}
\hline Pathologies & Ambulatory & Hospitalization & Total \\
\hline Chronic psychosis & 13 & 11 & 24 \\
\hline Depression & 19 & 1 & 20 \\
\hline Acute psychosis & 7 & 11 & 18 \\
\hline Polytoxicomania & 2 & 4 & 6 \\
\hline Bipolar disorder & 2 & 2 & 4 \\
\hline Pharmacopsychosis & 3 & 0 & 3 \\
\hline Others & 4 & 7 & 11 \\
\hline Total & 50 & 36 & 86 \\
\hline
\end{tabular}

Table 2: Pathologies diagnosed.

\begin{tabular}{|c|c|c|}
\hline DCI & Class & Dose (mg) \\
\hline Alimemazine $\left(n^{*}=1\right)$ & Antihistaminics & 7.5 \\
\hline Alprazolam (n=8) & Benzodiazepines & 0.78 \\
\hline Amitriptyline (n=29) & Antidepressors & 42.67 \\
\hline Bromazepam (n=3) & Benzodiazepines & 6 \\
\hline Captopril (n=1) & Antihypertensives & 50 \\
\hline Carbamazepine $(n=17)$ & Antiepileptics & 658.82 \\
\hline Chlorpromazine $(n=57)$ & Neuroleptics & 107.89 \\
\hline Clomipramine $(n=1)$ & Antidepressors & 25 \\
\hline Clonazepam (n=1) & Benzodiazepines & 2 \\
\hline Cyamemazine $(n=1)$ & Neuroleptics & 50 \\
\hline Diazepam (n=27) & Benzodiazepines & 13.33 \\
\hline Enalapril + nitrendipine $(n=1)$ & Antihypertensives & 10 \\
\hline Haloperidol $(n=57)$ & Neuroleptics & 8.86 \\
\hline Heptaminol $(n=1)$ & Vasodilators & 375.6 \\
\hline Hydroxyzine $(n=4)$ & Antihistaminics & 53.13 \\
\hline Levomepromazine $(n=6)$ & Neuroleptics & 91.67 \\
\hline Lorazepam (n=7) & Benzodiazepines & 3.75 \\
\hline Oxazepam (n=10) & Benzodiazepines & 49 \\
\hline Paracetamol $(n=1)$ & Analgesics & 2000 \\
\hline Prazepam $(n=2)$ & Benzodiazepines & 37.5 \\
\hline Promethazine $(n=17)$ & Antihistaminics & 72.06 \\
\hline Risperidone $(n=12)$ & Neuroleptics & 5 \\
\hline Tianeptine $(n=3)$ & Antidepressors & 25 \\
\hline Tiapride $(n=2)$ & Neuroleptics & 110 \\
\hline Trihexyphenidyle $(n=40)$ & Antiparkinsonians & 5 \\
\hline Tropatepine $(n=5)$ & Antiparkinsonians & 10 \\
\hline Zolpidem ( $n=7)$ & Hypnotics & 8 \\
\hline
\end{tabular}

Table 3: Profile of the drugs prescribed. 
Citation: Allabi AC, Klikpo E, Lonmandon SC, Tognide CM (2017) Pharmacovigilance of Neuroleptics and Benzodiazepines in the Psychiatric Teaching Hospital of Benin Republic. J Pharmacovigil 5: 249. doi:10.4172/2329-6887.1000249

Page 3 of 5

\section{Number of drugs prescribed per patient}

Hospitalized patients received more drugs including more neuroleptics than those treated ambulatory, but the number of benzodiazepines has been the same (Table 4 and Table 5).

\section{Observance and side events}

$91.86 \%$ of the patients took their medicines correctly. Nevertheless, $65.12 \%$ of all patients had at least one side event. The percentages of patients with $1,2,3,4$ and 5 side events were $39.28 \%, 41.07 \%, 8.92 \%$, $7.14 \%$ and $3.57 \%$ of the $65.12 \%$ respectively. The average number of side events per patient was similar in hospitalized patients and in those treated ambulatory (1.97 vs. 1.92). A total of 109 SEs was recorded, mainly sleep disturbances (insomnia: $22.09 \%$ and day sleeping: $17.44 \%)$. Table 6 displays the types and frequencies of the SEs. The causality assessment of the side events to the drugs prescribed to each patient is predominantly doubtful (52.29\%). It is likely in $44.95 \%$ of the cases, very likely in only $1.83 \%$ of the cases and plausible in $0.92 \%$ of the patients. There has been no case in which the side events were incompatible with the treatment. Table 7 specifies the side events related to drug-drug interactions and their types (PD or PK), while Table 8 indicates the time-to-event and shows its shortness (mostly during the first week and always during the first month).

\section{Discussion}

Adverse drug reactions characteristics and profiles among black African psychiatry patients are lacking. To our knowledge, it is first study reporting adverse drug reactions actively in psychiatry patients in west Africa. The size of the study population authorizes the recording

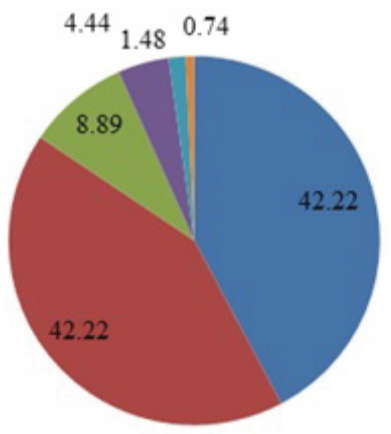

\section{- CHLORPROMAZINE}

- HALOPERIDOL.

$=$ RISPERIDONE

- LEV OME PROMAZINE

- TIAPRIDE

= CY AMEMAZTNE

Figure 1: First generation neuroleptics used

\begin{tabular}{|c|c|c|c|}
\hline Factor & All drugs & Neuroleptics & Benzodiazepines \\
\hline Mean & 3.73 & 1.57 & 0.76 \\
\hline Standard deviation & 0.12 & 0.07 & 0.07 \\
\hline Median & 4 & 3 & 2 \\
\hline Mode & 4 & 2 et 4 & 1 \\
\hline Minimum & 1 & 1 & 3 \\
\hline Maximum & 7 & 5 & 1 \\
\hline
\end{tabular}

Table 4: Number of drugs per patient.

\begin{tabular}{|c|c|c|c|c|c|}
\hline & \multicolumn{2}{|c|}{ Ambulatory $(n=50)$} & \multicolumn{2}{|c|}{ Hospitalized $(n=36)$} & \multirow[b]{2}{*}{$p$-value } \\
\hline & Average & SD & Average & SD & \\
\hline All drugs & 3.54 & 0.13 & 4 & 0.21 & 0.06 \\
\hline Neuroleptics & 1.38 & 0.1 & 1.83 & 0.09 & 0.002 \\
\hline Benzodiazepines & 0.72 & 0.09 & 0.8 & 0.11 & 0.55 \\
\hline
\end{tabular}

Table 5: Number of neuroleptics and benzodiazepines per in and outpatient.

\begin{tabular}{|c|c|c|}
\hline Events & Number & Frequency in $\%$ \\
\hline Insomnia & 19 & 22.09 \\
\hline Day sleeping & 15 & 17.44 \\
\hline Headache & 8 & 9.3 \\
\hline Fever & 6 & 6.98 \\
\hline Agitation & 5 & 5.81 \\
\hline Asthenia & 5 & 5.81 \\
\hline Better appetite & 4 & 4.65 \\
\hline Vertigo & 4 & 4.65 \\
\hline Diarrhoea & 3 & 3.49 \\
\hline Abdominal pain & 3 & 3.49 \\
\hline Acute dyskinesia & 3 & 3.49 \\
\hline High blood pressure & 3 & 3.49 \\
\hline Agressiviness & 2 & 2.33 \\
\hline Falls & 2 & 2.33 \\
\hline Chills & 2 & 2.33 \\
\hline Orthostatic hypotension & 2 & 2.33 \\
\hline Dry mouth & 2 & 2.33 \\
\hline Vomiting & 2 & 2.33 \\
\hline Anorexia & 1 & 1.16 \\
\hline Muscle cramps & 1 & 1.16 \\
\hline Pain in the eye & 1 & 1.16 \\
\hline Dyspnoea & 1 & 1.16 \\
\hline Night hypersialorrhea & 1 & 1.16 \\
\hline Hypoglycemia & 1 & 1.16 \\
\hline Arterial hypotension & 1 & 1.16 \\
\hline Urinary incontinence & 1 & 1.16 \\
\hline Instability & 1 & 1.16 \\
\hline Muscle stiffness & 1 & 1.16 \\
\hline Stereotypy of gestures & 1 & 1.16 \\
\hline Extrapyramidal symptoms & 1 & 1.16 \\
\hline Tachycardia & 1 & 1.16 \\
\hline Ocular twich & 1 & 1.16 \\
\hline Stiff neck & 1 & 1.16 \\
\hline Trembling of the hands & 1 & 1.16 \\
\hline Coca cola urines & 1 & 1.16 \\
\hline Nettle rash & 1 & 1.16 \\
\hline Swollen face & 1 & 1.16 \\
\hline
\end{tabular}

Table 6: Types and frequencies of the side events.

of the most frequent side events. In contrary to other studies that followed only hospitalized patients $[13,14]$ or ambulatory ones $[15,16]$. This study included both types of patients allowing a global view of the SEs' profile. The French method had been used to perform causality assessment because it helps collect data of good quality though its specificity is not the best compared to Naranjo et al., Jones's and WHO's.

As in other studies, acute and chronic psychoses were predominant (61.11\%). Though there are better neuroleptics, the second generation ones, the most prescribed neuroleptics to the study population are Chlorpromazine and Haloperidol, probably because of their lower cost. Interestingly, the average dose of Chlorpromazine $(107.89 \mathrm{mg} /$ patient/day) is four to seven times inferior to the one (401 à $800 \mathrm{mg} /$ day) recommended by a study in 2008 for optimal efficacy with few side events [17]. Janicak et al. suggested $300 \mathrm{mg}$ to $600 \mathrm{mg}$ [18]. Three reasons could explain the low dose of Chlorpromazine found in this study: the association with other psychotropic drugs, the recent character of the diagnoses and the higher sensitivity of the black African people to neuroleptics. On the other hand, the average dose of Haloperidol in 


\begin{tabular}{|c|c|c|}
\hline Interactions & Side events & Type of interaction \\
\hline \multirow{2}{*}{ Chlorpromazine+carbamazepine } & Arterial & Pharmacodynamic \\
\hline & Hypotension & Pharmacocinetic \\
\hline \multirow{5}{*}{ Chlorpromazine+haloperidol } & Better appetite & PD \\
\hline & Stereotypy of gestures & PD \\
\hline & Ocular twitch & PD \\
\hline & Trembling of the hands & PD \\
\hline & Neck stiffness & PD \\
\hline $\begin{array}{l}\text { Chlorpromazine+haloperidol+ } \\
\text { amitriptyline+trihexyphelidyle }\end{array}$ & Dry mouth & PD \\
\hline $\begin{array}{l}\text { Chlorpromazine +haloperidol } \\
\text { +diazepam }\end{array}$ & Day sleeping & PD \\
\hline \multirow{2}{*}{$\begin{array}{l}\text { Chlorpromazine+haloperidol+ } \\
\text { lorazepam }\end{array}$} & \multirow{2}{*}{ Nettle rash } & PD \\
\hline & & PK \\
\hline $\begin{array}{c}\text { Chlorpromazine } \\
\text { +haloperidol+oxazepam }\end{array}$ & Day sleeping & PK \\
\hline Chlorpromazine +risperidone & Acute dyskinesia & PD \\
\hline $\begin{array}{l}\text { Chlorpromazine +tropatepine+ } \\
\text { promethazine }\end{array}$ & Tachycardia & $\mathrm{PD}$ \\
\hline \multirow[b]{2}{*}{ Haloperidol+levomepromazine } & Acute dyskinesia & PD \\
\hline & $\begin{array}{l}\text { Extrapyramidal } \\
\text { symptoms }\end{array}$ & PD \\
\hline \multirow{2}{*}{ Haloperidol+lorazepam } & \multirow{2}{*}{ Insomnia } & PD \\
\hline & & PK \\
\hline \multirow{2}{*}{$\begin{array}{l}\text { Haloperidol+oxazepam+ } \\
\text { carbamazepine }\end{array}$} & \multirow{2}{*}{ Headache } & PD \\
\hline & & PK \\
\hline Risperidone + diazepam & Day sleeping & PD \\
\hline
\end{tabular}

Table 7: Side events related to drug-drug interactions.

this study is $8.86 \mathrm{mg} /$ day. Several studies indicate that smaller doses up to $2 \mathrm{mg}$ /day are as efficient with fewer side events [19-21].

Benzodiazepines are often combined to neuroleptics in psychiatry for better clinical results. The daily dose of diazepam, the most prescribed benzodiazepine in the present study is $13.33 \mathrm{mg}$ while Glen et al. have suggested $54 \mathrm{mg}$ for combinations [22]. The smaller dose of this study could be explained by the combination with antihistaminic. The high therapeutic observance by hospitalized patients compared to other studies $[23,24]$ is due to the permanent presence of a care giver and to the psycho education given in the department. Two main types of side events have been recorded. The neurological ones (the most frequent) followed by appetite improvement. The frequency of neurological SEs is $61.58 \%$ against $79.10 \%$ in a study by Khoda et al. [13] in India. Day sleeping occurred in $17.44 \%$ of the cases during the first three days of treatment and can be related to the sedative property of neuroleptics (action on $\mathrm{H} 1$ histaminic, al adrenergic and M1 muscarinic receptors) and to benzodiazepines (potentializing the depressive effect of the GABAergic transmission). Benzodiazepines are able to increase the plasma levels of neuroleptics thereby maximizing their effects [25]. Gao et al. [26] study on Haloperidol in psychotic patients found the median time-to-day sleeping to be three days. Abnormal movements are caused by neuroleptics. Their prevalence in this study is $5.81 \%$. A study by the American Psychiatric Association indicated $10 \%$ as the frequency of acute dyskinesia [27]. According to another study [28], 2 to $3 \%$ of patients put under neuroleptics develop a dyskinesia. The difference in these data is linkable to the profile of the molecules used. Weight gaining is a SE due to neuroleptics and can be explained by the improvement of the appetite. $4.65 \%$ of the patients experienced an increase of appetite; a number which is smaller than the

\begin{tabular}{|c|c|c|}
\hline Side events & Number & Time-to-event (days) \\
\hline Day sleeping & 15 & $1 ; 2 ; 3$ \\
\hline Better appetite & 4 & $1 ; 2 ; 10$ \\
\hline Headache & 4 & $4 ; 7 ; 9 ; 14$ \\
\hline Accute dyskinesia & 3 & $6 ; 7 ; 20$ \\
\hline Vertigo & 3 & $6 ; 7 ; 8$ \\
\hline Asthenia & 2 & $1 ; 15$ \\
\hline Orthostatic hypotension & 2 & $1 ; 7$ \\
\hline Insomnia & 2 & $10 ; 24$ \\
\hline Dry mouth & 2 & $8 ; 9$ \\
\hline Anorexia & 1 & 4 \\
\hline Muscule cramps & 1 & 22 \\
\hline Dyspnoea & 1 & 15 \\
\hline Arterial hypotension & 1 & 1 \\
\hline Urinary incontinence & 1 & 16 \\
\hline Muscule stiffness & 1 & 2 \\
\hline Stereotypy of gestures & 1 & 9 \\
\hline Extrapyramidal symptoms & 1 & 20 \\
\hline Tachycardia & 1 & 4 \\
\hline Ocular twich & 1 & 9 \\
\hline Neck stiffness & 1 & 8 \\
\hline Trembling of the hands & 1 & 3 \\
\hline Nettle rash & 1 & 18 \\
\hline Swollen face & 1 & 20 \\
\hline Vomiting & 1 & 2 \\
\hline
\end{tabular}

Table 8: Side events related to drug-drug interactions.

$78 \%$ of Pérez-Iglesias et al.' in Spain [29]. This variation is explainable by difference of classes of the neuroleptics prescribed in both settings. The occurrence of SEs calls for measures that could improve patients' quality of life. Doses have been reduced in $23 \%$ of the cases against $36 \%$ in India [13]. Possible strategies of an active monitoring, which could enable physicians to a possible prevention, early detection and a timely management of such adverse events should be developed in the psychiatry setting.

\section{Limitations}

The size of our study population does not allow the observation of rare SEs that occurs in one patient out of a thousand. In addition, only clinical adverse events were collected since laboratory tests were seldom prescribed.

\section{Conclusion}

At the National University Hospital of Benin, the main psychiatric diseases are psychoses in hospitalized patients $(61.11 \%)$ and depression in those followed ambulatory (38\%). Typical antipsychotics are more prescribed $(84.44 \%)$ than the second generation ones. Neuroleptics are more frequent in the treatment of hospitalized patients compared to external patients but the prescription of benzodiazepines does not vary in the two groups. Therapeutic observance is good (91.86\%) but side events involve $65.12 \%$ of the patients. Drug doses are reduced only in $23 \%$ of the cases while the product is stopped in $5.77 \%$ of those situations. Other studies could be added to this one to analyze biological side events, assess the weight gain linked to neuroleptics and better describe drug-drug interactions in psychiatry. Atypical antipsychotics should be made more available and pharmacovigilance developed in the country by installing a National Pharmacovigilance Center and by training the health personnel. 
Citation: Allabi AC, Klikpo E, Lonmandon SC, Tognide CM (2017) Pharmacovigilance of Neuroleptics and Benzodiazepines in the Psychiatric Teaching Hospital of Benin Republic. J Pharmacovigil 5: 249. doi:10.4172/2329-6887.1000249

\section{References}

1. World Health Organization (2004) Invest in mental health. Geneva: OMS, p: 49

2. Schuler D, Burla L (2002) Psychic health in Switzerland monitoring (Obsan Rapport 52). Neuchâtel, Swiss Health Observatory, p: 96.

3. Asouab F, Agoub M, Kadri N, et al. (2005) Prevalence of mental disorders in the Moroccan general population (National Survey 2005). Epidemiological Bulletin 33.

4. Agongbonou R (2013) Prevalence of schizophrenia in Ouidah health zoneKpomassé Tori Bossito in Benin. Thesis: Med: Cotonou; N 1688, p: 124.

5. Knuf A, Osterfeld M (2008) Psychotropic drugs: Information for an informed use of psychotropic drugs. Pro Healthy Mind 40.

6. Dorosz (2017) Practical Guide to Drugs. 36th edn. In: D Vital Durand, C Le Jeunne (eds) Malone.

7. Rittmannsberger $\mathrm{H}$, Meise U, Schauflinger K, Horvath E, Donat H, et al. (1999) Polypharmacy in psychiatric treatment: Patterns of psychotropic drug use in Austrian psychiatric clinics. Eur Psychiatry 14: 33-40.

8. Inserm (2012) Médicaments psychotropes: Consommations et pharmacodépendances. Paris INSERM (Collection Expertise Collective).

9. Nassir Ghaemi S, Shirzadi AA, Filkowski M (2008) Publication bias and the pharmaceutical industry: The case of lamotrigine in bipolar disorder. Medscape J Med 10: 211

10. Healy D (2009) Are selective serotonin reuptake inhibitors a risk factor for adolescent suicide? Can J Psychiatry 54: 69-71.

11. Word Health Organization (2000) Safety monitoring of medicinal products: Guidelines for setting up and running of a pharmacovigilance center.

12. Allabi AC, Nwokike J (2014) A situational analysis of pharmacovigilance system in republic of benin. J Pharmacovigilance 2:136.

13. Khoda DA, Ganachari MS, Wadhwa T, Walli S, Parihar B, et al. (2014) Clinica pharmacist driven impact towards intensive monitoring and reporting of adverse drug events in psychiatric patients. J Pharmacovigilance 2:128.

14. Jain T, Bhandari A, Ram V, Parakh M, Wal P, et al. (2011) Drugs interactions and adverse reactions in hospitalized psychiatric patients, a critical element in providing safe medication use. German J Psychiatry 14: 44-45.

15. Sengupta G, Bowmick S, Hazra A, Datta A, Rahaman M (2011) Adverse drug reaction monitoring in psychiatry out-patient department of an Indian teaching hospital. Indian J Pharmacol 43: 36-39.
16. Pivarva KG, Buch JG, Chandrani KV (2011) Analysis of adverse drug reactions of atypical antipsychotic drugs in psychiatry. Indian J Psychol Med 33: 153-157.

17. Dudley K, Liu X, De Haan S (2009) Chlorpromaqine dose for people with schizophrenia. Cochrane Database of Systematic Reviews 2: 1-43.

18. Janiack PG, Davis JM (1996) Antipsychotic dosing strategies in acute schizophrenia. Int Clin Psychopharmacol 11 (Suppl 2): 35-40.

19. Donnelly L, Rathbone J, Adams CE (2013) Haloperidol dose for acute phase of schizophrenia. Cochrane Database Syst Rev 8.

20. Davis JM, Chen N (2004) Dose response and dose equivalence of antipsychotics. J Clin Psychopharmacol 24: 192-208.

21. Oosthuizen P, Emsley R, Jadri Turner H, Keyter N (2004) A randomized controlled comparison of the efficacy and tolerability of low and high doses of haloperidol in the treatment of first episode psychosis. Int J Neuropsychopharmacol 7: 125-131.

22. Stimmel GL (1996) Benzodiazepine in schizophrenia. Pharmacotherapy 16 148S-151S.

23. Palazzolo J (2007) Drug compliance and schizophrenia. Mental Health 115 27-33.

24. Demoz Z, Legesse B, Teklay G, Demeke B, Eyob T, et al. (2014) Medication adherence and its determinants among psychiatric patients in an Ethiopian referral hospital. Patient Preference and Adherence 8: 1329-1335.

25. Gaillard R, Ouana A, Spadone C (2006) Benzodiazepines and schizophrenia literature paper. The Brain 32: 1003-1010.

26. Gao K, Mackle M, Cazorla P, Zhao J, Szegedi A (2013) Comparison of somnolence associated with asenapine, olanzapine, risperidone, and haloperidol relative to placebo in patients with Schizophrenia or bipolar disorder. Neuropsychiatric Disease Treatment 9: 1145-1147.

27. Raja M (1998) Managing antipsychotic induced acute and tardive dyskinesia. Drug Safety 19: 57-72.

28. Ayd FJ (1961) A survey of induced extrapyramidal reactions. JAMA 175: 1054 1060.

29. Perez-Iglesias R, Martinez-Garcia O, Pardo-Garcia C, Amado JA, GarciaUnzueta MT, et al. (2014) Course of weight gain and metabolic abnormalities in first treated episode of psyschosis: The first year is a critical period for development of cardiovascular risk factors. Int J Neuropsychopharmacol 17 $41-51$. 